\title{
S] ПОЛИТИЧЕСКИЕ
}

Владимирова Т.В.

\section{УРОВЕНЬ ИНТЕНСИВНОСТИ КОММУНИКАЦИИ КАК КРИТЕРИЙ ОБЕСПЕЧЕНИЯ ИНФОРМАЦИОННОЙ БЕЗОПАСНОСТИ}

\begin{abstract}
Аннотация: Предметом исследования является интенсивность коммуникаиии как критерий обеспечения информационной безопасности субъекта, где под информационной безопасностью понимается обеспечение безопасности соииальных практик информачионной среды, посредством новых мобильностей и ориентации в сетевом пространстве, в условиях роста интенсивности информачионных потоков и устаревания информащии. Такой подход задает соииальный внешний контур представления об информаџионной безопасности, сохраняя традиионное, более технологическое определение информаџионной безопасности, суть которого заключается в «защите информации и защите от информации». Теоретико-методологическим основанием исследования являются социально-философские и соииологические теории. В частности, используются идеи В. Н. Муравьева, Э. Тоффлера, 3. Баумана, соииология мобильностей Дж. Урри и др. Автор утверждает, что важнейшим аспектом новых соииальных мобильностей как практик обеспечения безопасности, является высокая интенсивность коммуникаций, выраженная в скорости и многообразии взаимодействия. Темпоральные характеристики соииальной практики имеют прямое отношение к обеспечению субъектом информационной безопасности. Лестница субъектов действия; люди прошлого, настоящего, будущего; человек пространства и человек времени - являются метафорами различения субъектов по их возможностям интенсивности информационного взаимодействия с миром. Чем выпе уровень интенсивности (скорости и разнообразия) коммуникаций, осуществляемых субъектом, тем в большей мере защищены его практики в условиях роста информационных потоков и устаревания информации.

Review: The subject under review is the intensity of communication as a criterion of information security of an individual where information security is understood as the safety of social practices in the information environment by the means of new mobilities and orientations of social networks under the conditions of growing intensity of informational flows and information deterioration. This approach allows to outline a social external contour of the idea of information security and keep to the traditional and more technological definition of the information security as the "protection of information and protection against information". The theoretical and methodological basis of research includes the theories of social philosophy and social studies. In particular, the author bases his research on V. Muravyev's, Alvin Toffler's and Zygmunt Bauman's ideas as well as the theory of mobilities offered by John Urry and etc. The author claims that the most important aspect of the new social mobility is the high intensity of communication expressed in the speed and variety of interaction. Temporal characteristics of social practice have a direct bearing on information security provided by an individual. The 'ladder' of actors; people of the past, present and future; the man of space and the man of time are all metaphors of actors with different intensity of information interaction with the world. The higher the intensity level (speed and variety) of communication performed by an individual is, the more his practices are protected under the conditions of growing informational flows and information deterioration.
\end{abstract}

Ключевые слова: интенсивность коммуникаиии, информационная безопасность, критерий информационной безопасности, темпоральные характеристики практики, новые сочиальные мобильности, практики обеспечения безопасности, рост информационных потоков, устаревание информации, рост временности ситуации, ускорение изменений.

Keywords: communication intensity, information security, criterion of information security, temporal characteristics of practice, new social mobilities, safety practices, growth of informational flows, information (data) deterioration, growth of situational temporality, acceleration of changes. 
$\mathrm{y}$

сложнение современной жизни, обусловленное нарастанием информационных потоков, определяют появление новых особенностей социальных практик в обществе. Такие особенности фиксируются в социальной теории в терминах «скорости и временности социальной ситуации», «степени проходимости социальных ситуаций» (Э. Тоффлер), «отношения ограниченного участия» (Э. Тоффлер, 3. Бауман, С. Леш и др.), «дальнодействия и отвлеченности» (В. Е. Кемеров), «объектуализации отношений или появления «объектцентрированной социальности» (К. Кнорр Цетина), «делокализации социальных действий, их извлечения из конкретного контекста и свободного перемещения в самых широких пространственно-временных рамках»; «контрфактуальность мышления и калькуляция рисков» (Э. Гидденс), «частично-непрерывное внимание» и «пост-многозадачное поведение, характеризующее стремление индивида быть живым узлом коммуникационной сети» (Л. Стоун). Дж. Урри отмечает, что растет значимость мобильных гибридов: устойчивых и все более тесных связей субъектов и объектов - машин, технологий, предметов, текстов, образов, физических средств и т. д. ${ }^{1}$

В целом, все эти особенности практик мы объединяем термином «новые социальные мобильности», который обретает популярность благодаря работе Дж. Урри «Социология за пределами обществ: виды мобильности для XXI столетия» ${ }^{2}$. Считаем, что выработка в современном социуме новых форм мобильности, в определенной степени, является реакцией приспособления к росту интенсивности потоков и сетей. Новые социальные мобильности рассматриваются нами как общие практики обеспечения информационной безопасности.

Обычно, информационными угрозами называют угрозы, исходящие от киберпространства (от виртуального мира). Но для нас важно понимание того, что само современное общество, в условиях роста интенсивности информационных потоков, вырабатывает новые социальные практики не только в Сети, но и в обычном мире «актуальной реальности», которые можно считать и практиками обеспечения безопасности субъектов. Соответственно, об обеспечении ин-

\footnotetext{
1 Урри Дж. Социология за пределами обществ: виды мобильности для XXI столетия / пер. с англ. Д. Кралечкина; Нац. исслед. ун-т «Высшая школа экономики», 2012. С.58.

${ }^{2}$ Там же.
}

формационной безопасности можно говорить в широком и узком смысле этого слова: информационная безопасность в условиях современного общества (актуальной социальной реальности) и информационная безопасность в условиях киберпространства (виртуальной социальной реальности). В первом случае речь идет о социальных практиках, адекватных скорости и многообразию современных коммуникаций. Во втором случае, речь идет о сетевых практиках, адекватных изменчивому виртуальному пространству сетей и потоков. Второй тип практик обеспечения информационной безопасности составляет частный случай первого. И первый тип, и второй тип социальных практик сводятся, к содержанию защиты информации и защиты от информации. Мы придерживаемся следующего подхода к определению информационной безопасности: информационная безопасность - это обеспечение безопасности социальных практик информационной среды, посредством новых мобильностей и ориентации в сетевом пространстве, в условиях роста интенсивности информационных потоков и устаревания информации. Наш подход к понятию информационной безопасности задает как бы социальный внешний контур представления об обеспечении безопасности субъекта. Этот контур очерчивает традиционное, прежнее (более технологическое) определение информационной безопасности, суть которого заключается в «защите информации и защите от информации». ${ }^{3}$

Сущчностным аспектом новых соцчиальных мобильностей является высокая интенсивность коммуникаций, выраженная в скорости и разнообразии взаимодействия акторов. Значение скорости действия, скорости принятия решений или, в целом, высокий уровень интенсивности коммуникации сложно переоценить в ведении информационного противостояния. «Скорости процессов оказываются завязаны не на движения, а на информационные потоки, на инструментальную коммуникацию. В современном обществе тем больше скорость жизни, чем менее люди движутся. Это не скорость движения, а скорость решений, скорость трансакций» (А. В. Назарчук) $)^{4}$ А. Г. Дугин

\footnotetext{
3 Владимирова T. В. Информационная безопасность: социологическая перспектива понятия // Национальная безопасность. - Nota bene. 2013. № 4 (27). - C. 597- 604. DOI: 10.7256/2073-8560.2013.4.7476.

${ }^{4}$ Назарчук А. В. Социальное время и социальное пространство в концепции сетевого общества // Вопросы философии
} 
утверждает, что скорость сетевых процессов такова, что даже недолго замешательства и тайм-аута, необходимого для освоения правил сетевых игр, достаточно, чтобы все потерять. ${ }^{5}$

В свое время Э. Тоффлер отмечал, что скорость и временность социальной ситуации возрастают несоразмерно возможностям человека. В условиях роста интенсивности информационных потоков человек, организация, другие социальные субъекты формируют новые практики поведения, направленные на обеспечение безопасности своих интересов. Это выражается в росте временности вещей в жизни человека, временности места пребывания, временности в отношениях между людьми, временности существования организации и сотрудничества с организацией, и, наконец, временности самой информации, идей, смыслов. «Для того чтобы выжить, предотвратить, то, что мы назвали шоком будущего, индивид должен стать бесконечно более адаптируемым и знающим, чем когда-либо раньше. Он должен искать абсолютно новые способы бросить якорь, ибо все старые корни - религия, нация, общность, семья и профессия - уже шатаются под ураганным натиском силы ускорения», - писал Э. Тоффлер. ${ }^{6}$

Темпоральные характеристики сочииальной практики имеют, на наш взгляд, прямое отношение к обеспечению субъектом информационной безопасности. Чем выше скорость разрешения той или иной операции, чем выше скорость адекватной реакции на изменения (новую информацию), тем выше защищенность самой практики (осуществляющей ее структуры, отдельного индивида) - защищенность ее информации (тезауруса) и защищенность от воздействия внешней, деструктурирующей информации.

Э. Тоффлер отмечал, что в современном обществе ускорение социальных изменений достигло такого уровня, при котором его уже нельзя при каком угодно большом воображении считать «нормальным». Люди, ускоряя темпы перемен, порывают с прошлым. Мы отказываемся от прежнего образа мыслей, от прежних чувств, от прежних приемов приспособления к изменяющимся условиям жизни. Социальный мир обрета-

№ 9. 2012. URL: http://vphil.ru/index.php?option=com_content $\&$ task $=$ view\&id $=598 \&$ Itemid $=52$

5 Дугин А. Г. Теоретические основы сетевых войн // Информационные войны №1 (5) 2008. С.8

${ }^{6}$ Тоффлер Э. Шок будущего / Пер. с англ. - М.: ООО «Издательство АСТ», 2001. С. 48. ет иные, совершенно незнакомые и часто неприемлемые для многих формы ${ }^{7}$.

А. Ю. Шеховцев рассматривает человека как «малую флуктуацию» информационного процесса и предлагает понимание личности как некоторый, определенным образом организованный объем пространства, узел сгущения энергии и информации. ${ }^{8}$ Соглашаясь с этим подходом, мы рассматриваем социального субъекта, в частности, личность в качестве информационной структуры, представленной единством информационного множества. Информационное множество, пребывает в составе мирового информационного множества в качестве элемента последнего возможно при условии единства или целостности элементов его составляющих. Его же мы можем представить в виде информационного процесса как наличия перехода от единства к множественности путем дифференциации и обособленности действия. Имея знание или изначально некоторую целостность, единство внутренней информации, вступая во взаимодействие с миром, личность или социальная система актуализирует ту или иную свою, внутреннюю информацию, реализуя ее в действии, и тем заявляет о себе; одновременно, субъект (личность или социальная система) воспринимает окружающую действительность посредством внешней информации, усваивая и адаптируя действительность, тем самым постоянно усваивая новую и новую информацию, отбирая ее и включая в состав своей внутренней информации или информационного множества.

Представление о подобном механизме взаимодействия с внешним миром мы находим и в структурно-функциональных социологических теориях, где субъектом является социальная система, структурируемая коммуникацией.

Ниже мы рассмотрим состояния субъекта (в частности, личности) его особенности относительно различных характеристик интенсивности социального информационного взаимодействия. Тем самым мы попытаемся организовать некоторое различение возможностей субъекта в обеспечении информационной безопасности.

Если информация - это передача значения, знака, а социальный процесс - это глобальная передача

\footnotetext{
${ }^{7}$ Там же.

${ }^{8}$ Шеховцев А. Ю. Информационное пространство человека в координатах межцивилизационной парадигмы // Информационная цивилизация. Под ред. В. Б. Устьянцева - Самара, 2000. C. 26.
} 


\section{Политика и общество 4 (112) • 2014}

знака, то ввиду ускорения социального процесса, качество передачи становится все более высоким, мобильным, высокочастотным. Информация или информационный процесс были отмечены сознанием, благодаря их высокой интенсивности (высокочастотности). Разум человека был в состоянии осмыслить феномен информации только на определенном этапе ускорения передачи, ускорения социальных изменений, когда социальные изменения стали «осязаемы» для отдельного сознания. Мы можем предположить, что скорость передачи информации определяет как минимум три типа субъекта.

В традициях русской философской мысли еще В. Н. Муравьев указывал на различные возможности людей в «овладении временем». Он отмечал, что изменение отношений вещей есть всегда изменение времени. ${ }^{9}$ Социальное ускорение, выраженное в росте интенсивности информационных потоков и изменение социального времени имеют явную взаимозависимость. Философ считает, что утверждение себя и укрепление своей деятельности как существование объединяющего центра (самореализация личности) и есть создаваемое сознанием преодоление внешнего времени.

Отметим, что В. Н. Муравьев выделяет внутреннее время и внешнее, то есть процесс внутреннего изменения вещей в индивидуально-личностном пространстве и процесс внешнего, объективного изменения вещей. Если трактовать учение В. Н. Муравьева «о преодолении времени» в рамках информационной парадигмы, то «преодоление» внешнего времени можно интерпретировать как его предвосхищение, то есть выход сознания на более высокий уровень интенсивности социального информационного взаимодействия (или более высокую частоту коммуникации), более высокий, нежели тот, который предлагает на данный момент социальная среда (в смысле будущего как более высокой частоты социальных изменений).

В. Н. Муравьев пишет, что «в меньшей степени сознательные системы» принудительно участвуют во времени, увлекаются безудержно его потоком. ${ }^{10}$ «Более сознательные существа» (для нас - это личность или определенная социальная система, способные утверждать себя в более высоких частотах информационного взаимодействия), хотя, в известной мере, подвластны времени, но вместе с тем обладают способностью делать его, влиять на социальные изменения. Другими

${ }^{9}$ Муравьев В. Н. Овладение временем. - М.,1998.

${ }^{10}$ Там же. С.153. словами, «более сознательное существо» - это существо, претендующее на более высокую интенсивность восприятия и обработки информации, соответственно, на более высокую интенсивность изменений.

Сущность мысли заключается в функции расширения в данном месте субъектности, которая всегда соответствует собирательному действию определенного множества. Сила действия зависит от объема множества информации, а затем от степени коллективного в нем согласия (целостности моментов бытия личности, степень интеграции элементов системы). Действие психических и социальных систем (Н. Луман) или «сознательного существа» «измеряется свойствами действующего множества - его мощностью (в смысле количества) и степенью его «внутренней соборности» (В. Н. Муравьев).

Философ определяет сознательную систему (личность) как наличие перехода от единства к множественности путем дифференциации и обособленности действия. Личность рассматривается как некоторое множество значений. Он пишет, что «единое, чтобы быть, должно быть многим. Вместе с тем, каждый частный центр или сознательная система повторяет в себе эту изначальную способность мира быть многими вещами. Каждая сознательная система есть частный и особый фокус мирового действия, в которой мир как будто возвращается к первоначальной и самой глубокой естественной способности своей - способности самоумножения и творчества. Извне это ощущается как мощь этого центра, изнутри как его свобода или разносторонность». ${ }^{11}$ На наш взгляд, здесь изложена одна из фундаментальных характеристик субъекта, пребывающего в мировом информационном пространстве (множестве) или же в условиях глобального информационных потоков.

В. Н. Муравьев рассуждает о степени сознательности как критерии для субъективности действия, который определяет деятеля. Если действие существа бессознательно - существо это исчезает как субъект, сливается с поглощающим его большим субъектом (миром как субъектом мировой причинности). В таком случае несознательное существо есть просто орудие, механический канал, через который изливается чужое действие мирового целого. Философ пишет о возможности построения лестницы (иерархии) актов и, соответственно, лестницы субъектов действия. Отличие этих субъектов есть всегда различие множеств инфор-

${ }^{11}$ Там же. С. 150. 
мации, составляющих такого рода субъектов. Субъект действия есть всегда выразитель и представитель множества, горизонт же его сознания есть горизонт этого множества. ${ }^{12}$ Другими словами, уместно говорить о степени состоятельности субъекта действия, о степени дальнодействия (В. Е. Кемеров). Личность охватывает то, что стоит вне ее и, превращая эти чуждые вещи в свой придаток, делает их частью самой себя. Внешняя информация становится достоянием сознания. Разум служит орудием этого превращения, рисуя заранее проект такого синтеза и предсказывая его пути. В. Н. Муравьев делает вывод: «с одной стороны, степень особности (индивидуализации) зависит от степени разумности или сознательности как показателя дифференциации системы; с другой стороны, та же сознательность интегрирует разобщенные действия индивидов и постольку объединяет их. Отсюда, самый глубокий смысл индивидуализации - это восхождение через максимальное обособление к максимальному единению всех вещей». ${ }^{13}$

Во второй половине XX в. Э. Тоффлер, рассуждая о проблемах социального ускорения, описывает три категории людей: человека будущего, человека настоящего и человека прошлого. Давая характеристики этим трем категориям, американский мыслитель приводит понятие «проходимости» вещей, мест, людей, организаций и информации через «канал» человеческого опыта. Интенсивность «проходимости» через канал опыта различна у этих трех категорий людей. Тоффлер трактует мир как «ускользающую ситуацию» и указывает на пять элементов, которые составляют эту ситуацию: вещи (в смысле предметы, окружающие человека), место пребывания индивида, люди, окружающие его и составляющие круг его общения, организации, в которых задействован и идеи, владеющие его сознанием в данный момент. Тоффлер утверждает, что каждый из этих элементов, становится все более краткосрочным или временным для современного человека. Он убедительно показывает на примерах американской, европейской истории второй половины XX века эту возрастающую временность. Процесс социального ускорения изменений в обществе, описываемый Тоффлером, являет, по сути, описание возрастающей интенсивности (частотности) социального информационного взаимодействия.

\footnotetext{
12 Там же. С. 151.

${ }^{13}$ Там же. С. 152.
}

Скорость перемен, интенсивность потоков имеет значение иногда более важное, чем направление перемен или потоков. Э. Тоффлер вводит два понятия: «ускорение» и «временность». «Если ускорение - это новая социальная сила, то временность - ее психологическая параллель, и без понимания ее роли в поведении современного человека все теории личности, вся наша психология не будут отвечать современным требованиям... Изменяя наше отношение к окружающим нас ресурсам, сильно расширяя диапазон перемен и, что наиболее важно, ускоряя их темп, мы безвозвратно порвали с прошлым. Мы отрезали себя от старых способов мышления, восприятия и адаптации... Мы должны знать, как ускорение и временность изменяют текстуру существования, выковывая из нашей жизни и психики новые, незнакомые формы» ${ }^{14}$ На наш взгляд, эти слова мыслителя характеризуют фундаментальную проблему субъекта, пребывающего в современных условиях глобальных информационных потоков.

Итак, Э. Тоффлер утверждал (1970), что жители Земли разделены не только по расовому, религиозному или идеологическому признаку, но также в какомто смысле и во времени. 70\% жителей Земли живут во многих отношениях так же, как жили их предки столетия тому назад (занятие сельским хозяйством). Это люди прошлого. Более 25\% населения Земли живут в промышленно развитых странах. Они живут современной жизнью. Они продукт первой половины XX в., сформированные механизацией и массовым образованием, воспитанные на оставшихся в памяти воспоминаниях о сельскохозяйственном прошлом своей страны. Они - люди настоящего. Оставшиеся 2 - 3\% населения планеты сосредоточены в главных центрах техно- и культурных перемен. Эти первопроходцы, считает Тоффлер, сегодня живут так, как другие будут жить завтра. Что отличает их? Они богаче, лучше образованы, более мобильны, чем большинство. Но что особенно отличает людей будущего - это то, что они попали в новый, ускоренный темп жизни. Они «живут быстрее», чем люди вокруг них. Некоторые глубоко привязаны к этому высокоскоростному темпу жизни. Они всячески пытаются вызвать его и чувствуют тревогу, напряжение и дискомфорт, когда темп жизни замедляется. ${ }^{15}$

Э. Тоффлер предлагает рассуждать о временности как о скорости оборота разных отношений в жиз-

\footnotetext{
${ }^{14}$ Тоффлер Э. Шок будущего / Пер. с англ. - М.: ООО «Издательство АСТ», 2001. С. 30.

15 Там же. С. $50-51$.
} 


\section{Политика и общество 4 (112) • 2014}

ни индивида. Каждый из нас может быть охарактеризован в терминах относительно низкой или высокой интенсивности (частотности) коммуникации. Для некоторых жизнь отмечена более низкой информационной частотой, чем для других. Люди прошлого и настоящего ведут жизнь с относительно «низкой временностью» - их отношения с миром (вещами, местами, людьми, организациями, идеями (информацией)) имеют тенденцию длиться долго. Скажем, что эти индивиды представлены «сознательными системами», которых характеризуют относительно небольшие информационные множества. Но люди будущего живут в условиях, в которых длительность коммуникаций сокращается, пропускная способность отношений чрезвычайно ускорена. Эти субъекты являют мощные информационные множества. Именно они призваны задавать тренды социального времени, влиять на будущее социума. (по Муравьеву, по Тоффлеру) В их жизни вещи, места, отношения с людьми, идеи и организационные структуры - все «расходуется» быстрее.

Отметим, что если «скорость оборота различных отношений» рассматривать с позиции информационного социального взаимодействия, то она, в некотором смысле, оборачивается все той же интенсивностью коммуникаций или информационного взаимодействия различных множеств информации «сознательных систем», которая характеризует силу той или иной «сознательной системы», ее информационного множества. Следовательно, мы можем отметить, что различение личности по силе ее множественности (в смысле множества информации), определение лестницы субъектов действия (В. Н. Муравьев) и различение человека прошлого, человека настоящего и человека будущего по степени интенсивности коммуникации, являются взаимодополняемыми и близкими.

3. Бауман отмечает, что «претензии в отношении будущего едва ли могут предъявляться теми, кто не контролирует свое настоящее, а именно такого контроля безнадежно лишено большинство обитателей глобализирующегося мира». ${ }^{16}$ Это большинство лишено контроля за настоящим потому, что наиболее важные факторы, определяющие их жизнь и социальное положение, а так же перспективы того и другого, не находятся в их руках. «Эти люди ничего, или почти ничего не могут сделать ни в одиночку, ни группой, чтобы вернуть эти факторы в сферу своего влияния.

${ }^{16}$ Бауман 3. Индивидуализированное общество. - М., 2002. C. 44 .
Территории, заселенные этими обездоленными людьми, напоминают собой аэродромы, на которые садятся и с которых взлетают воздушные суда глобального флота, причем делают это в соответствии с их собственными загадочным расписанием и маршрутами. Именно с этим странным воздушным движением связаны надежды людей на выживание. Ставка здесь делается не просто на выживание, а на сам образ жизни и даже образ мыслей об этой жизни». ${ }^{17}$

Раньше «близкое» имело преимущества перед «отдаленным», а товары и новости, происходящие из окрестных местностей, преобладали над прибывающими издалека. Границы локального сообщества обуславливались возможностями и скоростью передвижения, что, в свою очередь, определялось имеющимися средствами транспорта и связи. Пространство было значимым. Сегодня его значение утрачивается. Смысл пространства как препятствия или даже предела коммуникации изживает себя. 3. Бауман рассуждает о «девальвации места»: физическое, некибернетическое пространство, где имеют место невиртуальные связи, превращается всего лишь в площадку, для доставки, поглощения и переработки информации, которая по своей природе экстерриториальна и киберпространственна. ${ }^{18}$ Входным билетом в новую глобальную элиту, считает 3. Бауман, является «готовность к жизни среди хаоса» и способность «процветать в условиях неустроенности»..., умение «позиционировать себя в переплетении возможностей, а не оставаться парализованным одной пожизненной специальностью».

3. Бауман рассуждает о двух категориях людей. Вслед за мыслителем, мы бы определили их как - человек пространства и человек времени. «Время и пространство по-разному распределены между стоящими на разных ступенях глобальной властной пирамиды. Те, кто может себе это позволить, живут исключительно во времени. Те, кто не может, обитают в пространстве. Для первых пространство не имеет значения. При этом вторые изо всех сил борются за то, чтобы сделать его значимым» ${ }^{19}$ «Ощущение «территории», ныне беспомощное и никаким усилием воображения не представляющееся самодостаточным, утратило значительную долю своей ценности, свою привлекательность и притягательную силу для тех, кто может свободно пе-

\footnotetext{
17 Там же. С. 46.

18 Там же. С. 47

19 Там же. С. 51.
} 
редвигаться; оно становится ускользающей целью для всех, кто сам, не обладая подвижностью, желал бы замедлить либо остановить передвижения невероятно мобильных хозяев исчезающего порядка» ${ }^{20}$ Итак, «обладание подвижностью», обитание во времени (т.е. актуализация темпоральности) и игнорирование пространства - вот рецепты успеха в условиях потоковой информационной среды.

Человек пространства и человек времени, вслед за темпоральной типологией Э. Тоффлера, в какойто степени, является различением субъекта в условиях глобальных информационных потоков, где степень интенсивности передачи информации выступает критерием дифференциации современного субъекта (личности).

Скорость перемен, имеет значение совершенно отличное и иногда более важное, чем направление перемен (Э. Тоффлер). 3. Бауман, утверждая монопольное значение скорости в современном обществе, отмечает, что «у нас нет веских причин считать себя сторожами своих братьев, заботится о них, да вообще быть моральными - и в прагматически настроенном обществе бесполезные и бездействующие бедняки, получатели пособий не могут рассчитывать на веские доводы в пользу их права на счастье. Признаем откровенно: нет ничего «рационального» в принятии на себя обязательств, в том, чтобы заботится о других и вообще быть нравственным человеком» ${ }^{21}$

Направление изменений не играет сейчас принципиальной роли, это не так важно в условиях «ускользающей ситуации». Важно не исчезнуть для самой ситуации и, в лучшем случае, предвосхитить ее. Скорость, и еще раз скорость, проблема выбора направленности только тормозит.

Для процветания в условиях неустойчивости и неопределенности, в условиях нарастания информационных потоков и роста устаревания информации субъекту необходима адекватная реакция на высокую интенсивность коммуникации (социального информационного взаимодействия). Саму индивидуализацию личности европейская традиция понимает как основу «непрерывной и продолжающейся, вынужденной и всепоглощающей модернизации» (рационализации).

\footnotetext{
${ }^{20}$ Там же. С. 51.

${ }^{21}$ Там же. С. 103.
}

\section{Выводы}

Итак, мы определяем информационную безопасность как обеспечение безопасности социальных практик информационной среды, посредством новых мобильностей и ориентации в сетевом пространстве, в условиях роста интенсивности информационных потоков и устаревания информации. Такой подход задает социальный внешний контур представления об обеспечении информационной безопасности субъекта. Контур очерчивает традиционное, более технологическое определение информационной безопасности, суть которого заключается в «защите информации и защите от информации».

Сущностным аспектом новых социальных мобильностей как практик обеспечения безопасности, является высокая интенсивность коммуникаций, выраженная в скорости и многообразии взаимодействия. Субъекты действия обладают различными возможностями в обеспечении безопасности практик информационной среды. Темпоральные характеристики социальной практики имеют прямое отношение к обеспечению субъектом информационной безопасности. «Процветание в условиях неустойчивости, неопределенности», «в условиях ускользающей ситуации» предполагает «овладение временем» субъектом. В обеспечении информационной безопасности важно «не исчезнуть» для самой ситуации, «принудительно участвуя во времени», а, в лучшем случае, ситуацию предвосхитить.

Лестница субъектов действия (В. Н. Муравьев); люди прошлого, настоящего, будущего (Э. Тоффлер); человек пространства и человек времени (3. Бауман) - являются метафорами различения субъектов по их возможностям интенсивности информационного взаимодействия с миром. Чем выше уровень интенсивности (скорости и разнообразия) коммуникаций, осуществляемых субъектом, тем в большей безопасности он пребывает в смысле защищенности своих практик в условиях роста информационных потоков и устаревания информации.

При этом обратим внимание, что высокая интенсивность коммуникаций является важным, но не единственным условием обеспечения безопасности. В целом, наш подход к определению информационной безопасности как защищенности практик информационной среды предполагает снятие информационной неопределенности субъекта относительно существующих потенциальных и реальных угроз за счет контроля над мировым пространством и наличия возможно- 


\section{Политика и общество 4 (112) • 2014}

стей, условий и средств для отражения этих угроз, что в совокупности определяет уровень (степень) информационной безопасности каждого субъекта. ${ }^{22}$

\section{Библиография:}

1. Урри Дж. Социология за пределами обществ: виды мобильности для XXI столетия / пер. с англ. Д. Кралечкина; Нац. исслед. ун-т «Высшая школа экономики», 2012. С.58.

2. Владимирова Т. В. Информационная безопасность: социологическая перспектива понятия // Национальная безопасность. - Nota bene. 2013. № 4 (27). - C. 597-604. DOI: 10.7256/20738560.2013.4.7476.

3. Назарчук А. В. Социальное время и социальное пространство в концепции сетевого общества // Вопросы философии № 9. 2012. URL: http://vphil. $\mathrm{ru} /$ index.php?option $=$ com_content $\&$ task $=$ view\&id $=$ 598\&Itemid $=52$

4. Дугин А. Г. Теоретические основы сетевых войн // Информационные войны №1 (5) 2008. С.8.

5. Тоффлер Э. Шок будущего / Пер. с англ. - М.: ООО «Издательство АСТ», 2001. С. 48.

6. Шеховцев А. Ю. Информационное пространство человека в координатах межцивилизационной парадигмы // Информационная цивилизация. Под ред. В. Б. Устьянцева - Самара, 2000. С. 26.

7. Муравьев В. Н. Овладение временем. - М., 1998.

8. Тоффлер Э. Шок будущего / Пер. с англ. - М.: ООО «Издательство АСТ», 2001.

9. Бауман 3. Индивидуализированное общество. M., 2002.

10. Арсентьев М. В. К вопросу о понятии «Информационной безопасности» // Информационное общество, 1997. № 4 - 6. С. 48 - 50 .

11. Владимирова Т.В. К социальной природе понятия «информационная безопасность» // NB: Национальная безопасность. - 2013. - 4. - С. 78-95. URL: http://www.e-notabene.ru/nb/article_596.html

12. М. И. Бочаров, Т. И. Бочарова Глобальное коммуникативное пространство: проблемы безопасности общения // Национальная безопасность / nota bene. -2012 . - 4. - C. 47-51.

${ }^{22}$ Арсентьев М. В. К вопросу о понятии «Информационной безопасности» // Информационное общество, 1997. № $4-6$. C. $48-50$.
13. Урсул А.Д. Обеспечение национальной безопасности через приоритеты устойчивого развития // NB: Национальная безопасность. - 2013. - 1. - C. 1-61. URL: http://www.e-notabene.ru/nb/ article_325.html

14. Урсул А.Д. Синергетический подход к исследованию безопасности // NB: Национальная безопасность. - 2012. - 2. - C. 1-47. DOI: 10.7256/23060417.2012.2.207. URL: http://www.e-notabene.ru/ nb/article_207.html

15. Владимирова Т.В. Проблема устойчивости порядка как угроза безопасности // NB: Национальная безопасность. - 2013. - 2. - C. 67-87. URL: http:// www.e-notabene.ru/nb/article_590.html

16. Владимирова Т.В. Рост «потребности в Неотрицаемом» и безопасность общества // NB: Национальная безопасность. - 2013. - 3. - С. 136-157. URL: http://www.e-notabene.ru/nb/article_595.html

17. Царегородцев А.В., Ермошкин Г.Н. Базовые принципы построения дерева целей информационной безопасности среды облачных вычислений // Национальная безопасность / nota bene. - 2013. 5. - C. 69-79. DOI: 10.7256/2073-8560.2013.5.9583.

18. Царегородцев А.В. Построение деревьев целей для идентификации требований безопасности среды облачных вычислений // Национальная безопасность / nota bene. - 2013. - 5. - C. 51-68. DOI: $10.7256 / 2073-8560.2013 .5 .9587$.

19. Муреев К.П. Программный агент обеспечения контроля и безопасности участников интернет олимпиад // NB: Кибернетика и программирование. - 2013. - 6. - С. 6-11. URL: http://www.enotabene.ru/kp/article_10168.html

20. Г. Л. Акопов Политико-правовые угрозы распространения социально ориентированных интернеттехнологий // Национальная безопасность / nota bene. -2012 . - 2. - C. 60-67.

21. Р. М. Асланов, А. А. Морозов Системный анализ правового обеспечения информационной безопасности в Российской Федерации // Национальная безопасность / nota bene. - 2012. - 2. - C. 56-59.

\section{References (transliteration):}

1. Urri Dzh. Sotsiologiya za predelami obshchestv: vidy mobil'nosti dlya KhKhI stoletiya / per. s angl. D. Kralechkina; Nats. issled. un-t «Vysshaya shkola ekonomiki», 2012. S.58. 
2. Vladimirova T. V. Informatsionnaya bezopasnost': sotsiologicheskaya perspektiva ponyatiya // Natsional'naya bezopasnost'. - Nota bene. 2013. № 4 (27). S. 597-604. DOI: 10.7256/2073-8560.2013.4.7476.

3. Nazarchuk A. V. Sotsial'noe vremya i sotsial'noe prostranstvo v kontseptsii setevogo obshchestva // Voprosy filosofii № 9. 2012. URL: http://vphil.ru/ index.php?option $=$ com_content $\&$ task $=$ view\&id $=59$ $8 \&$ Itemid $=52$

4. Dugin A. G. Teoreticheskie osnovy setevykh voin // Informatsionnye voiny №1 (5) 2008. S.8.

5. Toffler E. Shok budushchego / Per. s angl. - M.: OOO «Izdatel'stvo AST», 2001. S. 48.

6. Shekhovtsev A. Yu. Informatsionnoe prostranstvo cheloveka v koordinatakh mezhtsivilizatsionnoi paradigmy // Informatsionnaya tsivilizatsiya. Pod red. V. B. Ust'yantseva - Samara, 2000. S. 26.

7. Murav'ev V. N. Ovladenie vremenem. - M.,1998.

8. Toffler E. Shok budushchego / Per. s angl. - M.: OOO «Izdatel'stvo AST», 2001.

9. Bauman Z. Individualizirovannoe obshchestvo. - M., 2002.

10. Arsent'ev M. V. K voprosu o ponyatii «Informatsionnoi bezopasnosti» // Informatsionnoe obshchestvo, 1997. № 4 - 6. S. $48-50$.

11. Vladimirova T.V. K sotsial'noi prirode ponyatiya «informatsionnaya bezopasnost'» // NB: Natsional'naya bezopasnost'. - 2013. - 4. - C. 78-95. URL: http:// www.e-notabene.ru/nb/article_596.html

12. M. I. Bocharov, T. I. Bocharova Global'noe kommunikativnoe prostranstvo: problemy bezopasnosti obshcheniya // Natsional'naya bezopasnost' / nota bene. - 2012. - 4. - C. 47-51.

13. Ursul A.D. Obespechenie natsional'noi bezopasnosti cherez prioritety ustoichivogo razvitiya // NB: Natsional'naya bezopasnost'. - 2013. - 1. - C. 1-61. URL: http://www.e-notabene.ru/nb/article_325.html
14. Ursul A.D. Sinergeticheskii podkhod k issledovaniyu bezopasnosti // NB: Natsional'naya bezopasnost'. - 2012. - 2. - C. 1-47. DOI: 10.7256/23060417.2012.2.207. URL: http://www.e-notabene.ru/ nb/article_207.html

15. Vladimirova T.V. Problema ustoichivosti poryadka kak ugroza bezopasnosti // NB: Natsional'naya bezopasnost'. -2013.-2. - C. 67-87. URL: http://www.enotabene.ru/nb/article_590.html

16. Vladimirova T.V. Rost «potrebnosti v Neotritsaemom» i bezopasnost' obshchestva // NB: Natsional'naya bezopasnost'. - 2013. - 3. C. 136-157. URL: http://www.e-notabene.ru/ nb/article_595.html

17. Tsaregorodtsev A.V., Ermoshkin G.N. Bazovye printsipy postroeniya dereva tselei informatsionnoi bezopasnosti sredy oblachnykh vychislenii // Natsional'naya bezopasnost' / nota bene. - 2013. 5. - C. 69-79. DOI: 10.7256/2073-8560.2013.5.9583.

18. Tsaregorodtsev A.V. Postroenie derev'ev tselei dlya identifikatsii trebovanii bezopasnosti sredy oblachnykh vychislenii // Natsional'naya bezopasnost' / nota bene. - 2013. - 5. - C. 51-68. DOI: 10.7256/20738560.2013.5.9587.

19. Mureev K.P. Programmnyi agent obespecheniya kontrolya i bezopasnosti uchastnikov internet olimpiad // NB: Kibernetika i programmirovanie. - 2013. - 6. - C. 6-11. URL: http://www.e-notabene.ru/kp/article_10168.html

20. G. L. Akopov Politiko-pravovye ugrozy rasprostraneniya sotsial'no orientirovannykh internet-tekhnologii // Natsional'naya bezopasnost' / nota bene.2012.-2.-C. 60-67.

21. R. M. Aslanov, A. A. Morozov Sistemnyi analiz pravovogo obespecheniya informatsionnoi bezopasnosti v Rossiiskoi Federatsii // Natsional'naya bezopasnost' / nota bene. - 2012. - 2. - C. 56-59. 